\title{
Differences in receptivity to gastrointestinal infections with nematodes in dairy ewes: Influence of age and of the level of milk production
}

\author{
H. Hoste ${ }^{\mathrm{a}, *}$, A.C. Rulie ${ }^{\text {a }}$, F. Prevot ${ }^{\mathrm{a}}$, J.P. Bergeaud ${ }^{\mathrm{a}}$, C. Grisez ${ }^{\mathrm{a}}$, \\ F. De La Farge ${ }^{\text {b }}$, P. Jacquiet ${ }^{\text {a }}$, P. Dorchies ${ }^{\text {a }}$ \\ ${ }^{a}$ UMR 1225 INRA/DGER, «Interactions Hôte Agent Pathogènes» 23 Chemin des Capelles, 31076 Toulouse Cedex, France \\ ${ }^{\mathrm{b}}$ Laboratoire de Biochimie, CHU Rangueil, 1 Av Jean Poulhes, 31403 Toulouse Cedex 4, France
}

Received 7 September 2004; received in revised form 13 January 2005; accepted 25 February 2005

\section{Abstract}

Resistance to anthelmintics in populations of gastrointestinal nematodes is a major concern in small ruminants. One solution to limit the spread of anthelmintic resistance is to apply treatments selectively by targeting the most susceptible animals within a flock. In dairy goats, previous studies have shown that, within a flock, goats in first lactation and those with high level of milk production were highly receptive to nematode infections. These results provided the rationale for targeted treatments. In dairy ewes, such epidemiological information on possible factors modulating the susceptibility to parasitism were still lacking. The objective of the current study was therefore to examine differences in the level of parasite infection and in the pathophysiological consequences in dairy ewes, depending on the age or on the level of milk production. In three farms, parasite egg excretion, and the serum concentrations of pepsinogen and inorganic phosphate were compared on one hand between primiparous and multiparous ewes; on the other hand, between ewes with the highest and the lowest level of milk production, within a cohort of 3-5-year old animals. Overall, the results did not indicate significant differences for both either the parasitological or pathophysiological measurements depending on the level of milk production. In contrast, significant differences were found according to age, indicating higher levels of infections in the primiparous ewes than in the multiparous ones and suggesting that this category of animals represents a particular parasitic risk within a flock.

(C) 2005 Published by Elsevier B.V.

Keywords: Dairy ewes; Parasitic nematodes; Susceptibility; Epidemiology; Selective treatment

\section{Introduction}

* Corresponding author. Tel.: +33 5611938 75; fax: +33561193944.

E-mail address: h.hoste@envt.fr (H. Hoste).
In small ruminants, the constant increasing development of anthelmintic resistances nowadays severely impairs the control of gastrointestinal trichostrongylo- 
sis based on chemical drugs (Sangster, 1999; Jackson and Coop, 2000). Resistances to the three main families of broad spectrum anthelmintics available for the control of trichostrongyles have now been described worldwide in most nematode species (Sangster, 1999; Jackson and Coop, 2000; Kaplan, in press). Therefore, there is an urgent need to seek alternative or complementary solutions to anthelmintics as well as to improve the use of the drugs currently available in order to preserve their efficiency in the future (Waller, 1999). In many countries, recommendations have been emitted to reduce the selection pressure for anthelmintic resistance in nematode populations. They rely mainly on a reduction in frequency of treatments, the respect of appropriate doses, the alternation of drug families and the preferred use of narrow spectrum anthelmintic when possible (Dash et al., 1985; Waller et al., 1995). Another recommendation to slow down the development of anthelmintic resistance within worm populations is to favour targeted anthelmintic treatments instead of their systematic use. The principle of targeted treatments is to give anthelmintics only to the most infected and/or the most susceptible animals within a flock. By leaving some animals untreated, the method allows to maintain a refugia of susceptible genes within the worm population and this will contribute to slow down the spread of anthelmintic resistance, by diluting resistance genes (Barnes et al., 1995; Sangster, 1999; Coles, 2002; Van Wyk, 2001).

One key point in any method of selective treatment lays in the identification of the animals to be treated. In tropical and subtropical areas where Haemonchus contortus is the dominant species, a method based on the individual evaluation of related clinical signs has been developed. Both in sheep and goats, it has been shown that this FAMACHA method lead to significant reductions in the number of treatments applied per flock although maintaining a good level of control of parasites (Van Wyk and Bath, 2002). On the other hand, in temperate countries where Haemonchus is not the most prevalent genus, a method, based on epidemiological data, has been proposed in dairy goats (Hoste et al., 2002a). Its rationale was provided by the assessment of differences in receptivity to parasites between does within a flock, depending on the age or on the level of milk production, and therefore characterising the animals to be treated preferentially. The same method appeared potentially applicable in milk producing sheep.
However, information on the influence of similar factors on the receptivity and/or susceptibility to nematode infections were not available for dairy ewes.

The present study was performed to determine within flocks of dairy ewes whether the age or the level of milk production might also modulate the response to gastrointestinal nematodes.

\section{Materials and methods}

The survey was conducted in 2002 in three dairy ewe farms, from one of the main areas of ewe milk production in France, i.e. the Basque Country. In the three farms, the ewes were grazing for the whole year with lambing time occurring in November-December. After 40 days spent for lambs, the ewes were milked from January to June/July. Three groups of 20 ewes were selected and surveyed within each farm. One group was composed with 20 ewes in first lactation which were randomly selected. The two other groups were composed with multiparous, adult ewes which were 3,4 or 5 years old. Within each farm, within the pool of these 3-5-year old animals, the ewes were classified according to their level of milk production, based on (i) the mean records of the previous year and (ii) the mean yield of the first month of lactation, i.e. at a time when nematode challenges were low. In each farm, after classification of the ewes according to these two criteria, the two additional groups of 20 multiparous ewes were composed, one corresponding to ewes with a relative high level of milk production and the second one corresponding to the ewes with the low level of production. The values of both criteria characterising these two subgroups of selected multiparous ewes per farm are described in Table 1.

During the grazing season, individual faecal and blood samples were taken from the 60 ewes per farm, four times per year, i.e. in February, at the end of March, in May and at the end of September. In the three farms, the ewes were treated with anthelmintics during summer, i.e. respectively, with closantel (Seponver ${ }^{\circledR}$ ) at the beginning of August and at the start of September in farms 1 and 2 and with fenbendazole (Panacur ${ }^{\circledR}$ ) at the beginning of August in farm 3 .

Individual faecal egg counts (FECs) were performed using a modified Mc Master method (Raynaud, 1970). These data were completed by larval cultures to as- 
Table 1

Mean values of the criteria used to discriminate between the 20 high producing and 20 low producing $3-5$-year old ewes in the three farms of the survey

\begin{tabular}{llccccc}
\hline & Farm 1 & Farm 2 & \multicolumn{2}{c}{ Farm 3 } \\
\hline Size of the flock (\% first lactation) & \multicolumn{3}{c}{$340(20.6 \%)$} & & $440(25 \%)$ & $180(27.8 \%)$ \\
Mean yield (1) & 2001 & 1 1st month 2002 & 2001 & 1 st month 2002 & 2001 & 1 st month 2002 \\
$\quad$ Low producers & 161 & 0.80 & 212 & 0.81 & 133.4 & 0.692 \\
High producers & 228 & 1.347 & 282 & 1.43 & 203.4 & 1.220 \\
\hline
\end{tabular}

sess the generic composition of nematode populations on each farm (Gevrey et al., 1963). The blood samples were collected by venipuncture into vacuum tubes and were used to measure the serum concentrations of pepsinogen and inorganic phosphate. Pepsinogen concentrations were measured according to the method described by Kerboeuf (1975). Inorganic phosphate concentrations were determined according to the method described by Robinson et al. (1971).

For all the measurements (faecal egg counts and pathophysiological parameters), the comparisons were performed using a repeated measure analysis of variance (SYSTAT 9.0 software for Windows 1998, SPSS Inc., Chicago, USA). Values of eggs per gram were log $(x+1)$ transformed before being compared.

\section{Results}

\subsection{Parasitological data}

\subsubsection{Egg excretion (Fig. 1)}

Overall, the levels of mean egg excretion in the three farms, in the different groups of ewes, remained under 500 eggs per gram with the only exception being the values measured in September for the group composed of the first lactating ewes in farm 3.

The statistical comparisons of the mean egg excretions between the high and the low producing ewes in each farm did not indicate any significant differences (Fig. 1a).

In contrast, the values of egg excretion were usually found to be higher in the first lactating ewes than in the multiparous ones in the three farms. This observation was confirmed through the statistical comparison of the mean egg excretions between the two groups which confirmed significant differences in farms 2 and $3(P<0.01)$ (Fig. 1b).

\subsubsection{Generic composition of nematode} populations (Fig. 2)

When pooling the data obtained on the four different sampling dates, the infective larvae of Teladorsagia sp. were found to represent, respectively, 78.0, 72.9 and $69.9 \%$ of the nematode larvae recovered from the larval cultures in the three farms. Haemonchus larvae were present on the three farms at a low level, ranging from 0 to $16.4 \%$ depending on the farm and the time of the year.
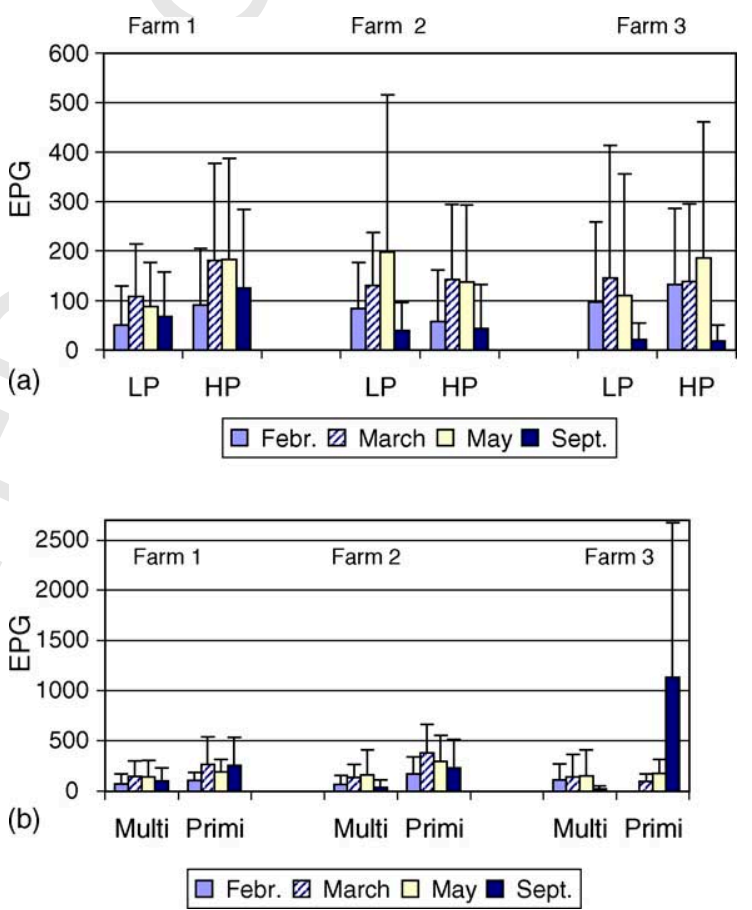

Fig. 1. Mean egg excretions in the three farms of the survey. (a) Comparison between high producing (HP) and low producing (LP) ewes; (b) comparison between multiparous vs. primiparous ewes. Significant statistical differences $(P<0.01)$ were assessed between the primiparous and multiparous ewes in farms 2 and 3 after values of egg excretion have been $\log (x+1)$ transformed. 


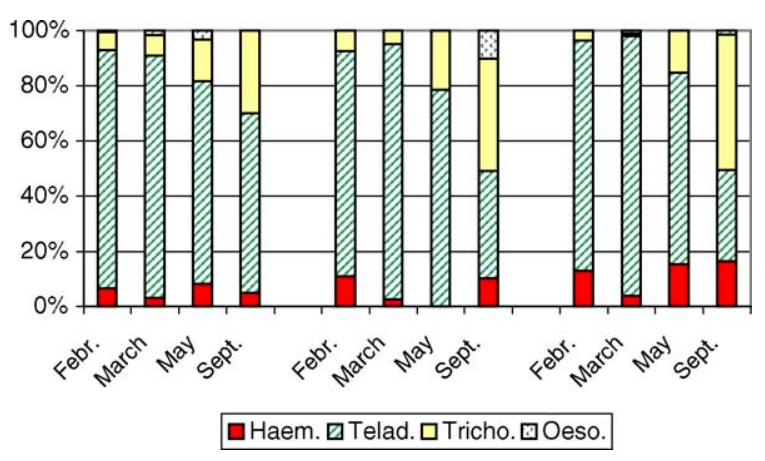

Fig. 2. Generic composition of the population of third stage infective larvae collected after larval culture in the three farms on the different dates of the survey.
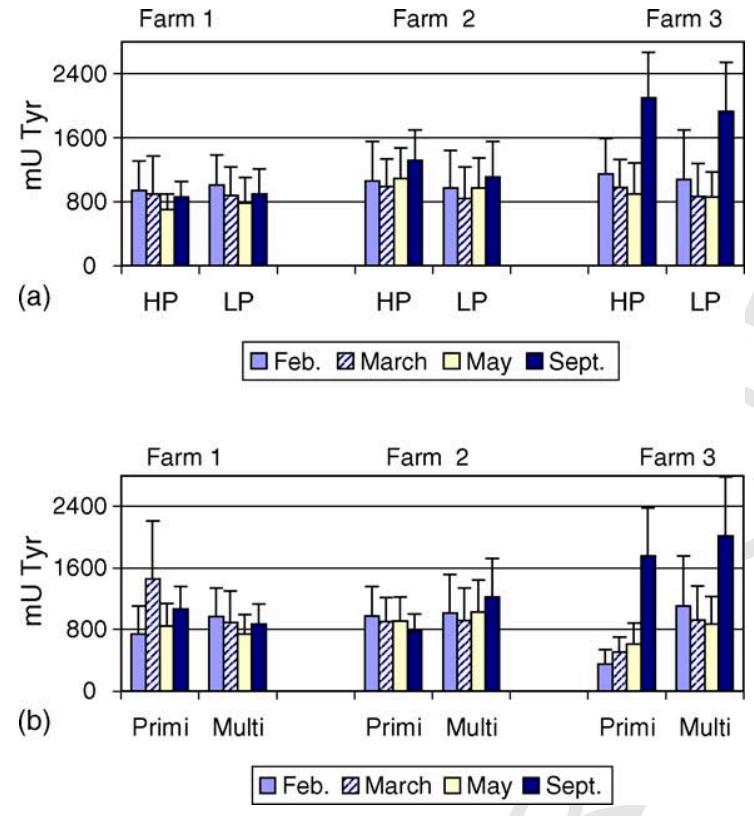

Fig. 3. Mean pepsinogen concentrations in the three farms of the survey. (a) Comparison between high producing (HP) and low producing (LP) ewes; (b) comparison between multiparous vs primiparous ewes. Significant statistical differences $(P<0.05)$ were assessed between the primiparous and multiparous ewes in farm 2.
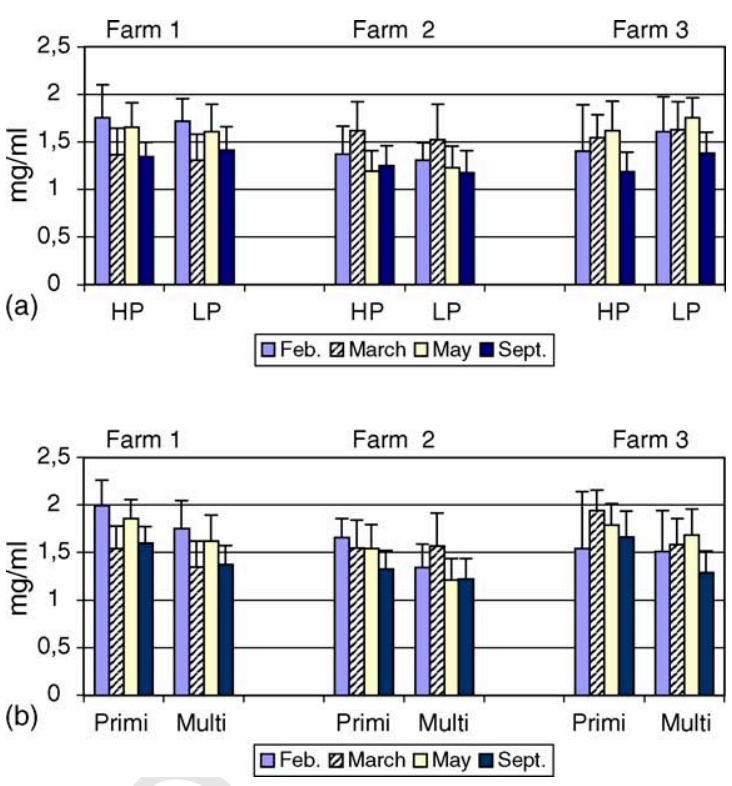

Fig. 4. Mean concentrations of serum inorganic phosphate in the three farms of the survey. (a) Comparison between high producing (HP) and low producing (LP) ewes; (b) comparison between multiparous vs. primiparous ewes. Significant statistical differences $(P<0.05)$ were assessed between the primiparous and multiparous ewes in farms 1 and 2.

high and the low producing adult ewes in the three farms did not indicate any differences between these two groups, with the exception of the phosphate values in farm 3, which were significantly lower in the HP than in the LP group $(P<0.04)$ (Figs. 3a and 4a).

In contrast, on the three farms, differences were repeatedly observed between the first lactating and the multiparous ewes both for the pepsinogen and the phosphate values (Figs. 3b and 4b). In general, these statistical differences corresponded to higher pepsinogen values and lower inorganic phosphate values found in the multiparous ewes compared to the primiparous ones. Significant differences between these two groups were found for the two measurements in farm 2 (pepsinogen: $P<0.05$; phosphate $P<0.01$ ), and for the phosphate values in farm $1(P<0.01)$.

\section{Discussion}

Overall, in the three farms, no statistical differences were found between the high and the low produc- 
ing ewes in the egg excretion at any date of the survey. This result suggests that a similar level of infection with gastrointestinal nematodes was present in the ewes regardless of the level of milk production. This conclusion is also supported by the lack of statistical differences in the two pathophysiological parameters which were measured. Because the blood concentrations of pepsinogen and inorganic phosphate are usually considered to reflect mucosal damage and thus, indirectly, the size of the worm populations occurring in the abomasum and in small intestine, respectively. This absence of difference tends to confirm a similar level of parasitism in the two subgroups of multiparous ewes.

In dairy goats, several studies have indicated that the high producing animals within a flock were less resistant and resilient to nematode infections than does from the same flock with a low level of milk production. Evidence supporting these conclusions have been acquired both in experimental infections (Hoste and Chartier, 1993; Chartier and Hoste, 1997) and through epidemiological surveys (Hoste et al., 1999, 2001, 2002b). It was postulated that such differences in host response depending on the level of production could be explained by the excessive nutritional demands related to high milk yield according to the nutritional framework proposed by Coop and Kyriazakis (1999).

Our results in dairy ewes are thus in contrast with data acquired in goats. Because the mean quantity of milk exported by dairy goats is nearly twice those excreted by ewes, it is suspected that the nutritional demands in ewes are less important than in goats, and this could explain the discrepancy. Moreover, in the current survey, half of the samples were taken at the end of lactation (May) or when ewes were out of production (September). On the other hand, it is also usually admitted that sheep are more likely than goats to exhibit an immune response against gastrointestinal nematodes (Pomroy et al., 1986; Huntley et al., 1995). Therefore, it can be postulated that the differences in response to parasites depending on the level of milk production might reflect some differences in the prioritisation of functions between the two small ruminant species.

Whereas only minor differences in parasitism were found between the ewes depending on the level of production, differences appeared to occur depending on the age, by the comparing primiparous and multiparous animals. This conclusion is supported by consistent results obtained for all three measurements. In the three farms, the egg excretions were generally higher in the first lactating ewes than in the multiparous ones and these differences were statistically significant on two farms. This result suggests the presence of higher worm populations in the youngest animals and is similar to previous findings in goats (Hoste et al., 1999, 2001, $2002 \mathrm{~b}$ ). As has been suggested for goats, it can be hypothesized that the higher receptivity of the first lactation ewes is due to the lack of or to the low intensity of previous contacts with trichostrongyles and the absence of an immune response able to regulate the worm populations as in older ewes.

Overall, when examining data from the three farms, the multiparous ewes were usually found to present higher pepsinogen and lower phosphate values. These results suggest that more severe pathophysiological changes occurred in the multiparous than in the primiparous ewes. Somehow, this appeared paradoxical with the lower levels of egg output found in the adult animals, suggesting lower levels of infections. However, this apparent contradiction might be explained if one postulates that the immune response developed by the adult ewes, which regulates the worm biology, also negatively affects the digestive tissues and functions of the host. Previous circumstancial evidence have been acquired supporting such a hypothesis of the involvement of some immunopathological processes in the origin of the structural and/or functional damages associated with the presence of gastrointestinal nematodes (Pullman et al., 1991; Larsen et al., 1999; Meeusen, 1999; Balic et al., 2000).

In dairy goats, the differences observed in receptivity and/or susceptibility between does within a flock depending on the age or on the level of production were used to provide the rationale for a selective application of anthelmintics (Hoste et al., 2002a). Our current results confirm that ewes in first lactation should represent the target of specific surveillance and possible selective treatments within dairy flocks as it has also been suggested in meat producing sheep (Leathwick et al., 1995). However, in multiparous ewes, it appears from our study that the identification of animals to be treated could not rely only on epidemiological information on differences in receptivity to nematode infection. Consequently, innovative methods of diagnosis should be developed and evaluated for this category of animals. 


\section{Uncited reference}

Sangster (2001).

\section{Acknowledgments}

The authors would like to thank first the three farmers who have accepted to participate in this study. Special thanks are also due to Dr. C. Vial-Novela, Dr. C. Gayrin and to Mr. J.M. Arranz, from the CDO Ordiarp, for their constant help during the whole survey. Last, the financial support from the PSDR programme from INRA and from the Région Midi-Pyrénées is sincerely acknowledged.

\section{References}

Balic, A., Bowles, V.M., Meeusen, E.N.T., 2000. The immunobiology of gastro intestinal nematode infections in ruminants. Adv. Parasitol. 45, 181-241.

Barnes, E.H., Dobson, R.J., Barger, I.A., 1995. Worm control and anthelmintic resistance: adventures with a model. Parasitol. Today $11,56-63$.

Chartier, C., Hoste, H., 1997. Response to challenge infection with Haemonchus contortus and Trichostrongylus colubriformis in dairy goats: differences between high- and low-producers. Vet. Parasitol. 73, 267-276.

Dash, K.M., Newman, R.J., Hall, E., 1985. Recommandations to minimise selection for anthelmintic resistance in nematode control programmes. In: Anderson, N., Waller, P.J. (Eds.), Resistance in Nematodes to Anthelmintic Drugs. Australian Wool Corporation Technical Publication, Melbourne, pp. 161-169.

Coles, G.C., 2002. Sustainable use of anthelmintics in grazing animals. Vet. Rec. 151, 165-169.

Coop, R.L., Kyriazakis, I., 1999. Nutrition-parasite interaction. Vet. Parasitol. 84, 187-204.

Gevrey, J., Takashio, M., Euzeby, J., 1963. Identification des strongles digestifs des ruminants par les caractères de diagnose de leurs larves infestantes. Bull. Soc. Vet. Med. Comp. 66, 133-147.

Hoste, H., Chartier, C., 1993. Comparison of the effects on milk production of concurrent infection with Haemonchus contortus and Trichostrongylus colubriformis in high- and low-producing dairy goats. Am. J. Vet. Res. 54, 1886-1893.

Hoste, H., Le Frileux, Y., Pommaret, A., Gruner, L., Van Quackebeke, E., Koch, C., 1999. Importance du parasitisme par des strongles gastro-intestinaux chez les chèvres laitières dans le Sud Est de la France. INRA Prod. Anim. 12, 377-389.

Hoste, H., Le Frileux, Y., Pommaret, A., 2001. The distribution and repeatability of fecal egg counts and blood parameters in dairy goats following natural infection with nematodes of the digestive tract. Res. Vet. Sci. 70, 57-60.
Hoste, H., Chartier, C., Le Frileux, Y., 2002a. Control of gastrointestinal parasitism with nematodes in dairy goats by treating the host category at risk. Vet. Res. 33, 531-546.

Hoste, H., Le Frileux, Y., Goudeau, C., Chartier, C., Broqua, C., Bergeaud, J.P., 2002b. Distribution and repeatability of nematode faecal egg counts in dairy goats: a farm survey and implications for worm control. Res. Vet. Sci. 72, 211-215.

Huntley, J.F., Patterson, M., Mckellar, A., Jackson, F., Stevenson, L.M., Coop, R.L., 1995. A comparison of the mast cell and eosinophil responses of sheep and goats to gastrointestinal nematode infections. Res. Vet. Sci. 58, 5-10.

Jackson, F., Coop, R.L., 2000. The development of anthelmintic resistance in sheep nematodes. Parasitology 120, 95-S107.

Kaplan, R.M., in press. Drug resistance in nematodes of veterinary importance: a status report. Trends Parasitol.

Kerboeuf, D., 1975. Le dosage du pepsinogène sanguin. Pfizer Actualités 16, 9-16.

Larsen, J.W.A., Anderson, N., Vizard, A.L., 1999. The pathogenesis and control of diarrhoea and breech soiling in adult Merino sheep. Int. J. Parasitol. 29, 893-902.

Leathwick, D.M., Vlassoff, A., Barlow, N.D., 1995. A model for nematodiasis in New Zealand lambs: the effect of drenching regime and grazing management on the development of anthelmintic resistance. Int. J. Parasitol. 25, 1479-1490.

Meeusen, E.N.T., 1999. Immunology of helminth infections with special reference to immunopathology. Vet. Parasitol. 84, 259-273.

Pomroy, W.E., Lambert, M.G., Betteridge, K., 1986. Comparison of faecal strongylate egg counts of goats and sheep on the same pasture. N.Z. Vet. J. 34, 36-37.

Pullman, A.L., Beveridge, I., Martin, R.R., 1991. Effects of challenge with trichostrongylid nematode larvae on immunologically resistant grazing yearling sheep in South Australia. Vet. Parasitol. 38, $155-162$.

Raynaud, J.P., 1970. Etude de l'efficacité d'une technique de coproscopie quantitative pour le diagnostic de routine et le contrôle des infestations parasitaires des bovins, ovins, équins et porcins. Ann. Parasitol. Hum. Comp. 45, 321-342.

Robinson, R., Roughan, M.E., Wagstaff, D.F., 1971. Measuring inorganic phosphate without using a reducing agent. Ann. Clin. Biochem. 8, 168-170.

Sangster, N.C., 1999. Anthelmintic resistance: past, present and future. Int. J. Parasitol. 29, 115-124.

Sangster, N.C., 2001. Managing parasiticide resistance. Vet. Parasitol. 98, 89-109.

Van Wyk, J.A., 2001. Refugia - overlooked as perhaps the most potent factor concerning the development of anthelmintic resistance. Onderstepoort J. Vet. Res. 68, 55-67.

Van Wyk, J.A., Bath, G.F., 2002. The FAMACHA system for managing haemonchosis in sheep and goats by clinically identifying individual animals for treatment. Vet. Res. 33, 508-529.

Waller, P.J., Dash, K.M., Barger, I.A., Le Jambre, L.F., Plant, J., 1995. Anthelmintic resistance in nematode parasites of sheep learning from the Australian experience. Vet. Rec. 136, 411-413.

Waller, P.J., 1999. International approaches to the concept of integrated control of nematode parasites of livestock. Int. J. Parasitol. $29,155-164$. 